\title{
Cranial Ultrasound in Moderate and Late Preterm Neonates: A Prospective Observational Study
}

\section{Om Krishna Pathak ${ }^{1}$, Yengkhom Rameshwor Singh ${ }^{2}$, Rahul Mugurkar ${ }^{3}$ and Pradeep Suryawanshi ${ }^{4}$}

${ }^{1}$ Department of Paediatrics, Bharatpur Hospital, Ministry of health, Government of Nepal, Nepal

${ }^{2}$ Department of Paediatrics, JN Institute of Medical Sciences, Imphal, Manipur, India

${ }^{3}$ Department of Paediatrics, Amrut Balrugnalaya, Auranganad, India

${ }^{4}$ Department of Neonatology, Bharati Vidyapeeth Deemed University Hospital, India

\author{
Correspondence: \\ Om Krishna Pathak \\ Department of Paediatrics, \\ Bharatpur hospital, \\ Ministry of Health, Government of \\ Nepal. \\ Email: dr.omkpathak@gmail.com
}

DOI: $10.3126 /$ jnps.v41i1.31024

Submitted on: 2020-09-05

Accepted on: 2020-02-19

\section{Acknowledgements: None}

Funding: Nil

Conflict of Interest: None declared

Permission from IRB: Yes

To cite this article: Pathak OK, Singh YR, Mugurkar R, Suryawanshi R. Cranial Ultrasound in Moderate and Late Preterm Neonates: A Prospective Observational Study. J Nepal Paediatr Soc. 2021;41(1):42-7.

\begin{abstract}
Introduction: Preterm infants' brain is vulnerable to ischemic and hemorrhagic injuries due to structural and molecular immaturities as well as associated co-morbidities, which is usually detected by bedside cranial ultrasound. Cranial ultrasound findings are common in preterm infants' of $<32$ weeks, so cranial ultrasound is routinely recommended in them but there is no such recommendation regarding moderate and late preterm infants. The objective of this study is to find the cranial ultrasound abnormalities in moderate and late preterm infants.
\end{abstract}

Methods: This prospective observational study was conducted in a tertiary level neonatal care unit. Hundred moderate and late preterm neonates delivered or admitted within seventh day of life were included in the study. Cranial ultrasound scan was performed between third and seventh day of life and before discharge and ultrasound findings were noted. Data were collected in predesigned case record form and analysed using Fischer Exact test.

Results: Out of 100 neonates, 47 (47\%) were males and $53(53 \%)$ females. There were $43(43 \%)$ moderately preterm and $57(57 \%)$ late preterm infants. Mean day of life for performing first and second cranial ultrasound was 4.17 (3 - 7) days and $13.24(3-40)$ days respectively. Cranial abnormalities were noted in $26 \%$ neonates. Intra-ventricular haemorrhage grade 1 or 2 was the commonest abnormality noted. Choroid plexus cyst (4\%), cerebral edema $(3 \%)$, periventricular hyperechogenicity $(3 \%)$ and hydrocephalus $(1 \%)$ were the other abnormalities noted. Neonates having APGAR $<6$ at one minute, mechanically ventilated and having co-morbidities had significantly higher incidence of abnormal findings.

Conclusions: It is reasonable to perform screening cranial ultrasound in high risk moderate and late preterm infants having low APGAR score, mechanically ventilated and having co-morbidities.

Key words: cranial ultrasound; late preterm; moderate preterm 


\section{INTRODUCTION}

A baby born after 37 weeks of gestation is defined as "term" infant. Babies born before 37 weeks of gestation are therefore termed as "Preterm." "1,2 Late preterm infants (LPIs) (defined as babies born between $34+0$ weeks and $36+6$ weeks gestation) and moderate preterm infants (MPIs) (defined as babies born between 32 weeks and $33+6$ weeks gestation) account for a large number of deliveries. ${ }^{3}$ In the world, preterm deliveries ranges from $5 \%$ to $18 \%$ in different parts of the world and largest number of preterm neonates are delivered in India. ${ }^{4}$ It is a well known fact that preterm infants are more vulnerable with increased morbidity and mortality in comparison to their counterpart term infants. Because preterm infants, especially those younger than 32 weeks gestation, are prone to both haemorrhage in the vulnerable areas of brain known as germinal haemorrhage and / or intraventricular haemorrhage (IVH) and ischemic white matter injuries, routine cranial ultrasound examinations are recommended for this group. ${ }^{5}$ American Academy of Neurology and the Practice Committee of the Child Neurology Society suggested screening all preterm neonates $<30$ weeks for severe IVH. ${ }^{6}$

Though less frequent than early preterm, moderate preterm and late preterm neonates can also develop IVH and ischaemic white matter injuries. Late and moderate preterm infants have an increased risk of morbidities such as temperature instability, respiratory distress syndrome (RDS), sepsis, hypoglycaemia, etc which along with the structural and molecular immaturity of premature brain have detrimental effect on the developing brain. ${ }^{7-9}$

Ultrasound is increasingly being used in neonatal intensive care management in last few years. Cranial ultrasound (CUS) examinations have been performed on preterm infants to diagnose various perinatal brain injuries and for the prediction of long term outcomes. ${ }^{1}$ Although other imaging modalities like magnetic resonance imaging (MRI) may be better in diagnosing certain brain injury, CUS has an advantage in that it can be done at bed side and it is cost effective. The information provided by CUS has often resulted in change in management. ${ }^{8}$ Identification of neonates with brain abnormalities at CUS would allow early neurobehavioral intervention programs to improve long-term outcomes.

We therefore decided to perform CUS screening program in late and moderate preterm infants to describe the pattern of abnormalities and to assess the potential need for CUS according to the perinatal risk factors. Studies have suggested that $48 \%$ IVH occurred within six hours of life and $>90 \%$ IVH occurred in fourth to fifth postnatal life. ${ }^{3,9}$ In a recent study by Ballardini et al. in late preterm infants, intracranial lesions were found in $13 \%$ of the neonates within seven days of life. Hence we decided to perform CUS first between third and seventh day of life, and second before discharge to note the neurological abnormalities in moderate and late preterm infants.

\section{METHODS}

This prospective observational study was conducted in a tertiary level Neonatal care unit of a medical college in Western India during $1^{\text {st }}$ March 2017 to $28^{\text {th }}$ February 2018. All the moderate and late preterm neonates delivered or admitted within seventh day of life in the hospital during the study period were included in the study. The study was started after obtaining the ethical approval from the Ethics Committee of our institute. Details of demographic characteristics like name, gender, date of birth, birth weight etc were collected using preset case record form. The gestational age was assessed and recorded within 48 hours of birth. Gestational age was calculated from first trimester USG findings. If USG report is not available, gestational age was calculated from date of Last Menstrual Period (LMP). If LMP dates are not available, New Ballard Score would be used to determine the gestational age.

Cranial ultrasound was performed by Consultant Neonatologist with more than 10 years experience in cranial ultrasound, first between third day of life and seventh day of life, and again before discharge. We used the SIEMENS ultrasound machine (Acuson X 300, SIEMENS Medical Solution) with a neonatal probe $(4-8 \mathrm{~Hz}$ transducer). Any abnormal findings during the CUS were noted. 
Data were entered in SPSS 19 and analysed using Fischer Exact test.

\section{RESULTS}

Total 100 moderate and late preterm neonates were enrolled in the study period, out of which 47 were males and 53 were females. Among the study population, 43 were moderately preterm and 57 were late preterm infants. Similarly, out of 100 neonates, 41 were delivered by caesarean section whereas 59 had spontaneous vaginal delivery, 30 were twins whereas 70 were singleton babies and 30 were small for gestational age. Twenty percent neonates were very low birth weight and $38 \%$ were born in different hospitals and transferred to our centre. Only $1 \%$ neonate had APGAR $<6$ at 5 minutes. The mean birth weight was 1833.81 grams (994 - 3190 grams).

Seventy five neonates had some or other form of co-morbidities. The commonest issues noticed were hyperbilirubinemia $(52 \%)$, followed by sepsis $(23 \%)$ and respiratory distress syndrome (RDS) (17\%). Fourteen neonates had several comorbidities and required mechanical ventilation (Table 1).

Mean day of life for performing first and second cranial ultrasound were 4.17 days ( $3-7$ days) and 13.24 days ( $3-40$ days) respectively. Only $17 \%$ of neonates had abnormal first CUS whereas $26 \%$ of neonates had abnormal CUS findings in one of the scanning (Table 2). More than 50\% (Nine out of 17 neonates) had IVH grade 1 or 2 , followed by

Table 1. Co-morbidities associated with LPIs and MPIs

\begin{tabular}{|lrr|}
\hline Comorbidities & Frequency & \multicolumn{1}{c}{ Percent } \\
\hline TTNB & 6 & 6.0 \\
RDS & 17 & 17.0 \\
Hypogylcemia & 5 & 5.0 \\
Hyperbilirubinemia & 52 & 52.0 \\
HIE & 4 & 4.0 \\
NEC & 1 & 1.0 \\
Sepsis & 23 & 23.0 \\
Others & 16 & 16.0 \\
\hline
\end{tabular}

cerebral edema (4\%), choroid plexus cysts $(3 \%)$, and periventricular hyperechogenicity (1\%) as CUS abnormalities in first scan while three fourth (15 out of 20 neonates) had IVH followed by periventricular hyperechogenicity $(3 \%)$, cerebral edema (1\%) and hydrocephalus (1\%) in second CUS. Only one neonate had grade 3 IVH, rest being either grade 1 or 2 .

Neonates having APGAR $<6$ at one minute, mechanically ventilated and having co-morbidities had significantly higher incidence of abnormal CUS findings (Table 3 ).

\section{DISCUSSION}

Preterm birth is associated with various brain injuries. The earlier the period of gestation, more is the incidence of brain injuries. Brain injuries are known to be one of the most important factors leading to significant morbidity and mortality in these vulnerable preterm babies. It is difficult to predict the future outcome of injured preterm brain and is a subject of intense research. CUS has been proved to be very useful equipment to evaluate neonatal brain. CUS is non invasive, quick as well as relatively cost effective modality of investigation. It also has the advantage of having no significant radiation hazard like other neuroimaging modalities. It is a bedside technology which can be easily repeated any time. Hence, CUS is the preferred modality of neonatal brain imaging in NICUs. ${ }^{11}$ However, it is very much operator dependent and not very specific. Among various

Table 2. Frequency of abnormal CUS findings

\begin{tabular}{|l|l|rr|}
\hline \multicolumn{2}{|l|}{ CUS abnormalities } & Frequency & Percent (\%) \\
\hline CUS 1st & No & 83 & 83.0 \\
Abnormal & Yes & 17 & 17.0 \\
& Total & 100 & 100.0 \\
\hline CUS 2nd & No & 61 & 75.3 \\
\hline Abnormal & Yes & 20 & 24.7 \\
& Total & 81 & 100.0 \\
\hline CUS Any & No & 74 & 74.0 \\
\hline abnormal & Yes & 26 & 26.0 \\
& Total & 100 & 100.0 \\
\hline & & & \\
\hline
\end{tabular}


Table 3. Association of abnormal CUS with different variables

\begin{tabular}{|c|c|c|c|c|c|}
\hline \multirow{2}{*}{ Characteristics } & \multirow{2}{*}{ Category } & \multicolumn{2}{|c|}{ Abnormal CUS } & \multirow[t]{2}{*}{ Total } & \multirow[t]{2}{*}{ p-value } \\
\hline & & No & Yes & & \\
\hline \multirow[t]{2}{*}{ Sex } & Female & $42(79.2 \%)$ & $11(20.8 \%)$ & $53(100 \%)$ & 0.204 \\
\hline & Male & $32(68.1 \%)$ & $15(31.9 \%)$ & $47(100.0 \%)$ & \\
\hline \multirow[t]{2}{*}{ POG } & Moderate pre-term & $29(67.4 \%)$ & $14(32.6 \%)$ & $43(100.0 \%)$ & 0.194 \\
\hline & Late pre-term & $45(78.9 \%)$ & $12(21.1 \%)$ & $57(100.0 \%)$ & \\
\hline \multirow[t]{2}{*}{ Mode of delivery } & CS & $43(72.9 \%)$ & $16(27.1 \%)$ & $59(100.0 \%)$ & 0.760 \\
\hline & SVD & $31(75.6 \%)$ & $10(24.4 \%)$ & $41(100.0 \%)$ & \\
\hline \multirow[t]{2}{*}{ Twins } & No & $52(74.3 \%)$ & $18(25.7 \%)$ & $70(100.0 \%)$ & 0.921 \\
\hline & Yes & $22(73.3 \%)$ & $8(26.7 \%)$ & $30(100.0 \%)$ & \\
\hline \multirow[t]{2}{*}{ SGA } & No & $55(78.6 \%)$ & $15(21.4 \%)$ & $70(100.0 \%)$ & 0.111 \\
\hline & Yes & $19(63.3 \%)$ & $11(36.7 \%)$ & $30(100.0 \%)$ & \\
\hline \multirow[t]{2}{*}{ LBW } & No & $61(76.3 \%)$ & $19(23.8 \%)$ & $80(100.0 \%)$ & 0.305 \\
\hline & Yes & $13(65.0 \%)$ & $7(35.0 \%)$ & $20(100.0 \%)$ & \\
\hline \multirow[t]{2}{*}{ Apgar $<6$ at 1 minute } & No & $72(79.1 \%)$ & $19(20.9 \%)$ & $91(100.0 \%)$ & 0.001 \\
\hline & Yes & $2(22.2 \%)$ & $7(77.8 \%)$ & $9(100.0 \%)$ & \\
\hline \multirow[t]{2}{*}{ Apgar $<6$ at 5 minutes } & No & $74(74.7 \%)$ & $25(25.3 \%)$ & $99(100.0 \%)$ & 0.260 \\
\hline & Yes & $0(0.0 \%)$ & $1(100.0 \%)$ & $1(100.0 \%)$ & \\
\hline \multirow[t]{2}{*}{ Outborn } & No & $47(75.8 \%)$ & $15(24.2 \%)$ & $62(100.0 \%)$ & 0.599 \\
\hline & Yes & $27(71.1 \%)$ & $11(28.9 \%)$ & $38(100.0 \%)$ & \\
\hline \multirow[t]{2}{*}{ Ventilated } & No & $70(81.4 \%)$ & $16(18.6 \%)$ & $86(100.0 \%)$ & 0.000 \\
\hline & Yes & $4(28.6 \%)$ & $10(71.4 \%)$ & $14(100.0 \%)$ & \\
\hline \multirow[t]{2}{*}{ Comorbidities } & No & $23(92.0 \%)$ & $2(8.0 \%)$ & $25(100.0 \%)$ & 0.018 \\
\hline & Yes & $51(68.0 \%)$ & $24(32.0 \%)$ & $75(100.0 \%)$ & \\
\hline
\end{tabular}

brain lesions, posterior fossa lesions, diffuse white matter injury and visualisation of myelination process aren't easily depicted by CUS. It is for this reason that in such scenario, MRI brain remains the choice of neuroimaging modality and would prove to be invaluable and perhaps irreplaceable. ${ }^{12}$ Despite this fact, the role of CUS in preterm brain injury can't be undermined. However, among preterm babies, generally there is inclination of considering only early preterm neonates with brain injuries. And hence, CUS is more often used to study brain injury in early preterm babies usually. However, in moderate and late preterm babies also, there is chance of similar brain pathology. Hence, we planned to study the role of CUS in moderate and late preterm neonates.

We had found that incidence of any abnormal CUS findings $26 \%$ in our study. This finding is similar to other studies done in India where abnormal CUS was $25.4 \%$ in neonates $<34$ weeks and in Egypt where abnormal findings were noted in $37 \%$ preterm infants. ${ }^{13,14}$ Similarly, another study done in Italy showed abnormal cranial ultrasound findings in $27 \%$ and $6 \%$ preterm infants respectively, for infants born at $33-34$ weeks and at $35-36$ weeks of gestational age respectively. ${ }^{10}$ 
Considering the abnormal CUS findings in our study, we found that there were significantly higher abnormal cranial ultrasound findings in neonates having APGAR $<6$ at 1 minute, mechanically ventilated and having co-morbidities $(\mathrm{p}<0.05)$. This finding is corroborated in other researches in the past too. In a study done in Italy, Monica et al found significantly higher abnormal CUS findings in late preterm infants having lower APGAR score and co-morbidities including mechanical ventilation. Similarly in another study in Italy, Ballardini et al. found association of abnormal CUS with microcephaly, low APGAR score at 5 minutes, co-morbidities requiring mechanical ventilation or surfactant and neurological abnormalities. ${ }^{10}$ Further corroborating to our findings, a study done in India by Jha et al. also found abnormal CUS results in preterm infants less than 34 weeks born to mothers with antepartum haemorrhage, with birth asphyxia, low birth weight and males. ${ }^{13}$

Most common abnormal CUS finding in our study was IVH, which was present in $15 \%$ of neonates in one of the scans. The IVH which we found most were of grades 1 or 2 except one grade 3 IVH. Similar to our study, IVH was the commonest CUS abnormalities in a study done in USA by Bhat et al. ${ }^{16}$ among preterms of $30-34$ weeks but with approximately $6 \%$ incidence whereas it was periventricular leukomalacia followed by IVH in another large study done in Italy by Ballardini et al. ${ }^{10}$ Higher incidence of IVH in our study is probably due to the need of transportation of neonates to our centre from other centres of various distance as $38 \%$ of neonates in our study were out born and referred to our centre for further management.

We acknowledge that our study has some limitations. Since we had done the study in a single centre tertiary hospital, our findings may not be generalised to al the hospitals as our centre receives more referral cases than a general hospital. We also did not study the follow up CUS and clinical importance of the CUS findings and long term neurodevelopmental outcome in the babies with abnormal CUS findings. Our findings should be corroborated with further studies with larger sample size in different centres.

\section{CONCLUSIONS}

It is a well known fact that neonates under 37 weeks of gestation have higher probabilities of having co-morbidities and adverse neonatal outcome, more so in earlier gestational age. Point of care cranial ultrasound helps to detect some of those co-morbidities and their complications early in moderate and late preterm infants as well. Though not routinely recommended, it is reasonable to perform screening cranial ultrasound in high risk moderate and late preterm infants having low APGAR score, mechanically ventilated and having co-morbidities.

\section{REFERENCES}

1. World Health Organisation. The Prevention of Perinatal Mortality and Morbidity. Report 457 Geneva, Switzerland: WHO Technical Report Series, 1970. Geneva: WHO;1970.

2. American Academy of Paediatrics and the American College of Obstetricians and Gynecologists 2005 Guidelines for Perinatal Care, 5th Ed. American Academy of Paediatrics, Elk Grove Village, IL, pp 211-20.

3. Raju TN, Higgins RD, Stark AR, Leveno KJ. Optimizing care and outcome for late-preterm (near-term) infants: a summary of the workshop sponsored by the National Institute of Child Health and Human Development. Paediatrics. 2006;118(3):1207-14; DOI: https://doi.org/10.1542/peds.2006-0018.

4. World Health Organisation. Preterm birth. Available from http://www.who.int/mediacentre/factsheets/fs363/en/ visited on $05 / 09 / 2020$

5. Batton DG, Holtrop P, De Witte D, Pryce C, Roberts C. Current gestational age-related incidence of major IVH. J Pediatr. 1994;125:623-5. https://doi.org/10.1016/S0022-3476(94)70023-0 
6. Ment LR, Bada HS, Barnes P, Grant PE, Hirtz D, Papile LA, et al. Practice parameter neuroimaging of the neonate: report of the Quality Standards Subcommittee of the American Academy of Neurology and the Practice Committee of the Child Neurology Society. Neurology. 2002;58:1726-38. DOI: 10.1212/wnl.58.12.1726

7. Wang ML, Dorer DJ, Fleming MP, Catlin EA. Clinical outcomes of near-term infants. Pediatrics. 2004;114(2):3726. DOI:https://doi.org/10.1542/peds.114.2.372

8. El-Khuffash A, Herbozo C, Jain A, Lapointe A, McNamara PJ. Targeted neonatal echocardiography (TnECHO) service in a Canadian neonatal intensive care unit: a 4-year experience. J Perinatol. 2013;33:687-90. DOI: 10.1038/ jp.2013.42

9. Al-Abdi SY, Al-Aamri MA. A systematic review and meta-analysis of the timing of early intraventricular hemorrhage in preterm neonates: Clinical and research implications. J Clin Neonatol. 2014;3:76-88. DOI: $10.4103 / 2249-4847.134674$

10. Ballardini E, Tarocco A, Baldan A, Antoniazzi E, Garani G, Borgna-Pignatti C. Universal cranial ultrasound screening in preterm infants with gestational age 33-36 weeks. A retrospective analysis of 724 newborns. Pediatr Neurol. 2014;51:790-4. DOI: 10.1016/j.pediatrneurol.2014.08.012

11. Van Wezel-Meijler G, Steggerda SJ, Leijser LM. Cranial ultrasonography in neonates: role and limitation. Semin Perinatol. 2010;34:28-38. DOI: 10.1053/j.semperi.2009.10.002

12. Maalouf EF, Duggan PJ, Counsell SJ, Rutherford MA, Cowan F, Azzopardi D, et al. Comparison of findings on cranial ultrasound and magnetic resonance imaging in preterm infants. Pediatrics. 2001;107:719-27. DOI: 10.1542/ peds.107.4.719

13. Ruchi J, Alka S, Richa J. Cranial Ultrasound In High Risk Preterm. Indian J Paediatr. 2017;6(1):1-5.

14. Nadia B, Amira E, Dahlia El S, Mohamed El G. Cranial Ultrasonographic Screening of The Preterm Newborn. Alexandria J Pediatr. 2005 Jul;19(2):347-56.

15. Fumagalli M, Ramenghi LA, Carli AD, Bassi L, Farè $\mathrm{P}$, Dessimone $\mathrm{F}$ et al. Cranial ultrasound findings in late preterm infants and correlation with perinatal risk factors. Ital J Pediatr. 2015;41:65. DOI: 10.1186/ s13052-015-0172-0

16. Bhat V, Karam M, Saslow J, Taylor H, Pyon K, Kemble N, et al. Utility of performing routine head ultrasounds in preterm infants with gestational age 30-34 weeks. J Matern-Fetal Neo M. 2012;25(2):116-9. DOI: 10.3109/14767058.2011.557755. 